\title{
Environmental Standard, Quality Improvement, and Technology Transfer
}

\author{
Ming-Chung Chang ${ }^{1}$ and Ching-Ti Pan ${ }^{*}, 2$
}

${ }^{1}$ Department of Banking and Finance, Kainan University, Taiwan
${ }^{2}$ Institute of Business and Management, National Chiao Tung University, Taiwan

\begin{abstract}
With technology licensing on quality innovation becoming a general phenomenon in the industry, this study focuses on the impact of quality improvement under different environmental standards. We established a three-country model to analyze the actions taken by the domestic firm located in the home country with high quality technology, the foreign firm located in the foreign country with low quality technology, and the products they export to the third country. The importing country also decides on an environmental standard for reducing environmental pollution. Our major findings are: (1) A less strict environmental standard is preferable for the third country government in the beginning, but the government will become stricter with the increasing substitution of products in the long term. (2) In the aspect of licensing, the higher quality firm tends to provide an option to draw up a royalty licensing contract rather than a fixed-fee licensing contract. (3) The social welfare of the high quality firm is always higher than that of the low quality firm, but it will decrease with the increasing substitution of products. Coming from the increasing substitution of products, the excess profit that is created for the low quality firm is used as a cost for pollution abatement. Therefore, the social welfare of the foreign country does not change when the substitution of product changes. This model fully illustrates the real case of mainland China and enriches the field of technology licensing on quality innovation.
\end{abstract}

JEL Codes: L11, L51, O13.

Keywords: Environmental standard, quality improvement, technology transfer.

\section{INTRODUCTION}

The concept of sustainable development in recent years has obtained agreement throughout the United Nations. The environmental concern of sustainable development includes pollution abatement, conservation of national resources, prevention of global warming, etc. The 3E (economy, environment, and energy) initiative provides a platform for sustainable development. Based on this concept, many ecological economists and neoclassical economists point out that trade and environment are critical to sustainable development [1].

The same importance goes for economic development and environmental protection. In order to balance the two, many countries have set an environmental standard to ban pollution products after using them as imports. The United States Environmental Protection Agency (EPA) and the EU-implemented Energy Efficiency Center (EEC) regulate strict emission standards that limit China's exports of motorcycle tricycles (a motorcycle with three wheels) to their markets [2]. Under World Trade Organization (WTO) regulations, it is forbidden to use trade policies to benefit home firms. Although WTO agreements do not regulate that governments cannot use environmental policies as strategic instruments in trade, many scholars also believe beer should be sold in bottles rather than cans in Denmark in order to

*Address correspondence to this author at the Institute of Business and Management, National Chiao Tung University, 118, Sec. 1, Chung-Hsiao West Road, Taipei City 100, Taiwan; Fax: 886-2-23494922;

E-mail: judy081@gmail.com protect domestic beer producers against German ones. Another interesting point is that a stricter environmental policy may hinder technology expansion when a government sets up emission taxes and environmental standards as instruments to protect the environment or local firms [3]. As a result, it is important to analyze the issue of technology transfer under strategic environmental policy in trade.

\section{LITERATURE REVIEW}

Barrett [4] considers environmental policies in an exogenous firm location model where two countries are competing to export to a third country. The number of firms in his model is fixed, and his main purpose is to compare the results under Cournot competition with that under Bertrand competition. There is an environmental dumping effect in his model when non-cooperative trade exists. It may be optimal to set an equilibrium tax below the Pigouvian level for internalizing environmental damages through the tempered ability of the government to shift rent. Kayalica and Lahiri [5] present strategic environmental policies in the context of foreign direct investment (FDI), with their model being extended to consider the role of free entry and to allow the amount of FDI to be endogenous as in Lahiri and Ono [6]. Moreover, they introduce a trade instrument, i.e., export subsidy, to examine how it affects the results of environmental policies. The important implication in their outcome is that when an export subsidy is applied, the market structure with an endogenous number of foreign firms has no effect on environmental policies. 
Dean [7] believes that a stricter environmental policy weakens a country's comparative advantage in the international trading market. A strategic action for maintaining a competitive advantage is the licensing of environmental technologies. Gallini [8] notes that a leading firm is willing to share an innovation with a follower firm through a license contract, because sharing innovation decreases the incentive of the rival to develop better technology. Hence, the global trend is for governments to encourage the domestic and international licensing of environmental technologies, as the licensing of environmental technologies benefits economic growth and environmental protection.

Many established articles on technology licensing focus on cost-reducing technology innovation [9-14], but the literature of technology licensing on quality innovation is rather limited. A vehicle industrial product with a significant difference in quality is a rich source of motivation for quality technology licensing. For instance, the Environmental Protection Administration of Taiwan began to regulate motorbike emission standards on January 1, 1988, calling for an emission standard in the first stage. Thereafter, motorbike emission standards in Taiwan turned stricter during the following stages: the second stage was implemented on July 1, 1991, the third stage on January 1, 2002, the fourth stage on January 1, 2004, and the fifth stage on July 1, 2007. The emission standards of the fifth stage correspond to the European Emission Standard's third stage (EU3), which is the strictest emission standard in the world. It is noteworthy that the Ministry of Environmental Protection of the People's Republic of China also implemented a new emission standard as strict as EU3 on July 1, 2007. Motorbikes that do not adhere to the new emission standard cannot be sold after July 1, 2008 [15].

There is a closer relationship between quality technology licensing and environmental protection in real life. The ISO (International Organization for Standard) 9001 certification refers to requirements for a quality management system whereby a firm needs to demonstrate its ability to provide a product that meets customers' needs and regulatory requirements for enhancing customer satisfaction through an effective application of the system. It includes processes for continual improvement of the system and assurance of conformity to customer and applicable regulatory requirements. ISO 14001 is an environmental management standard, making up a set of environmental management requirements for environmental management systems that can be used by all types of firms to protect the environment, to prevent pollution, and to improve environmental performance. One example in the vehicle manufacturing industry is that the fiberglass electric vehicle bodywork manufactured by Jiangsu Jiuding New Material Co. adheres to both ISO 9001 and ISO 14001 [16].

Past studies have held divergent views when analyzing the firm's preference of technology licensing methods. Wang [17] extends the homogeneous goods model to a differentiated goods duopoly model with the firm's output under the fixed-fee licensing method more than that under the royalty licensing method, indicating that fixed-fee licensing is always superior to royalty licensing by consumers. However, Chang et al. [18] consider environmental factors to investigate the optimal licensing method which depends on the social welfare under a homogeneous duopoly when one of the firms owns the innovation related to environmental technology. Their results argue that consumers are likely to prefer royalty licensing to fixed-fee licensing. Thus, it is worthwhile to study a firm's preference on a technology licensing contract, because some controversy still exists when considering an environmental policy.

This paper analyzes the impact of quality improvement under the role of international trade and the existence of environmental policies. We establish a three-country model - the domestic firm locates in the home country with high quality technology, the foreign firm locates in the foreign country with low quality technology, and they export products to the third country - to fill an important gap in the established literature by considering the strategic licensing of environmental technologies in the presence of a product's quality promotion.

The remainder of this paper is as follows. Section 2 illustrates our model set-up. Section 3 derives and compares the equilibrium properties of pre-licensing, the fixed-fee licensing contract, the royalty licensing contract, the optimal licensing contract, and the optimal environmental standard. Section 4 offers an equilibrium analysis of the optimal licensing contract and the optimal environment standard. Finally, Section 5 makes some concluding remarks.

\section{MODEL SET-UP}

This paper adopts the three-country model proposed by Brander and Spencer [19] in which the home firm and the foreign firm export a product to the third country and extend this with Cournot competition. We also assume the home firm (Firm 2) has a high quality innovation and the foreign firm (Firm 1) does not, with both producing a heterogeneous product in the final goods market. The home firm decides a technology licensing method and then the foreign firm decides whether to accept technology licensing or not. The third country government sets the optimal environmental standard for maximizing the social welfare.

Firm 1's product quality is $s_{1}$ and Firm 2's product quality is $s_{2}$. To simplify notation, let $s_{1}=\gamma$ and $s_{2}=1$, where $\gamma \in(0,1)$ and $s_{1}=\gamma s_{2}$. The two products have a closer substitution when the parameter $\gamma$ is large. A small $\gamma$ stands for a large quality difference. We further assume that all products are sold in the third country and the two firms' production costs and transportation costs are 0 .

The consumer's utility function is: $V=\left\{\begin{array}{l}u s_{i}-p_{i}, \text { if the consumer purchases a product with quality } s_{i}, \\ 0, \text { if the consumer does not purchase anything, }\end{array}\right.$ where $i=1$ or 2 . The parameter $u \in(0,1)$ is the uniform distribution and the destiny function is 1 . The population is normalized to 1 , and $p_{i}$ is the product price.

Some products cause pollution after using, such as a high quality motorbike under a strict emission standard still discharging a little pollution into the air when it is run. However, a low quality motorbike will emit a lot of exhaust gases into the air. Hence, we assume that the pollution 
amount per unit for the low (high) quality product is $e_{1}\left(e_{2}\right)$. It is reasonable to assume that a low quality product emits a high pollution amount and a high quality product emits a low pollution amount. Thus, we assume that $e_{2}=0$ and $e_{1}=1-\gamma$. It is obvious that the emission amount of the low quality product decreases when there is quality promotion.

We use the parameter $z$ to indicate the third country's environmental standard, where $z \in(0,1)$. The parameter $z$ shows a maximum allowed pollution amount of per unit product. A strict (less strict) environmental standard corresponds to a small (large) $z$. Under an environmental standard, an abatement level of per unit product for a low quality firm is $1-\gamma-z$, where $z \leq 1-\gamma$. Since there is no pollution from a high quality firm's product after using it, the environmental standard does not have any influence to a high quality firm. For a simplified analysis, we assume that per unit product abatement cost is 1, i.e., $c=1$. All symbols in the calculation process arranged with their nomenclature are described in Appendix.

\section{MODEL ANALYSIS}

We solve the three-stage game by backward induction to obtain the Nash equilibrium. In the first stage, the third country sets an environmental standard to maximize its social welfare. In the second stage, the home firm chooses the optimal technology transfer mode, either a fixed-fee contract or a royalty contract, and the foreign firm decides whether to accept the offer. In the third stage, the two firms simultaneously decide the output.

\section{Pre-Licensing Equilibrium}

We consider a benchmark model in which technology licensing does not occur. In this case, the two firms' quality levels are $s_{1}=\gamma$ and $s_{2}=1$, respectively. Using the approach provided by Motta [20], Avenel and Caprice [21], and Li and Song [14], the inverse demand functions of the two firms are: ${ }^{1}$

$p_{1}=\gamma\left(1-q_{1}-q_{2}\right)$ and $p_{2}=1-\gamma q_{1}-q_{2}$.

The profit functions are $\pi_{1}=p_{1} q_{1}-c(1-\gamma-z) q_{1}$ and $\pi_{2}=p_{2} q_{2}$, where $c=1$. Differentiating the profit functions of the two firms with respect to their own output and letting them be equal to 0 , i.e., $\partial \pi_{1} / \partial q_{1}=0$ and $\partial \pi_{2} / \partial q_{2}=0$, we obtain the equilibrium output, price, and profit:

$q_{1}{ }^{B}=\frac{3 \gamma+2 z-2}{\gamma(4-\gamma)}$ and $q_{2}{ }^{B}=\frac{3-2 \gamma-z}{4-\gamma}$,

$p_{1}{ }^{B}=\frac{\gamma^{2}-2 \gamma+2-2 z+\gamma z}{4-\gamma}$ and $p_{2}{ }^{B}=\frac{3-2 \gamma-z}{4-\gamma}$,

$\pi_{1}^{B}=\frac{(3 \gamma-2+2 z)^{2}}{\gamma(4-\gamma)^{2}}$ and $\pi_{2}^{B}=\frac{(3-2 \gamma-z)^{2}}{(4-\gamma)^{2}}$.

\footnotetext{
${ }^{1}$ The marginal consumer who is indifferent between purchasing the high quality product and the low quality product is decided by $u s_{1}-p_{1}=u s_{2}-p_{2}$. Hence, we have $u_{1}=\left(p_{2}-p_{1}\right) /(1-\gamma)$. The marginal consumer who is indifferent in purchasing the low quality product and purchasing nothing is decided by $u_{0}=p_{1} / \gamma$. Hence, the demand functions of the two firms are $q_{2}=\int_{u_{1}}^{1} d p=1-\left(p_{2}-p_{1}\right) /(1-\gamma)$ and $q_{1}=\int_{u_{0}}^{u_{1}} d p=\left(p_{2}-p_{1}\right) /(1-\gamma)-p_{1} / \gamma$.
} The inverse demand functions are thus $p_{1}=\gamma\left(1-q_{1}-q_{2}\right)$ and $p_{2}=1-\gamma q_{1}-q_{2}$.
The superscript $B$ stands for the equilibrium values in the benchmark model. To guarantee the equilibrium values are non-negative, i.e., $q_{1}{ }^{B} \geq 0$ and $q_{2}{ }^{B} \geq 0$, the constraints as follows have to be satisfied:

$1-\frac{3}{2} \gamma \leq z \leq 1-\gamma$

Since we assume that all products are sold in the third country, the social welfare of the home country is only composed of the home country firm's profit. Hence, the social welfare of the home country is represented as:

$W_{2}^{B}=\pi_{2}^{B}=\frac{(3-2 \gamma-z)^{2}}{(4-\gamma)^{2}}$.

The comparison statistic results show that $\partial W_{2}^{B} / \partial z=2(-3$ $+2 \gamma+z) /(4-\gamma)^{2}<0$ and $\partial W_{2}^{B} / \partial \gamma=2(3-2 \gamma-z)(5+z) /(-4$ $+\gamma)^{3}<0$. When the environmental standard becomes strict (parameter $\mathrm{z}$ decreases), the home country's social welfare increases, because an environmental standard raises the marginal abatement cost of the foreign country firm and then decreases the rival firm's output. This induces the home country firm's output to increase, resulting in a rise in the home country firm's profit. Therefore, a strict environmental standard is good for the country that produces the high quality product. When the product's degree of substitution increases, it increases the market competitive degree and then decreases the profit of the home country firm.

\section{Fixed-Fee Licensing Contract}

This section considers the technology transfer by means of a fixed-fee contract. After licensing, the two firms have the same product quality, i.e., $s_{1}=s_{2}=1$. The two firms engage in homogeneous product competition. The inverse demand function that they face is:

$p=1-q_{1}-q_{2}$.

The profit functions of the two firms are $\pi_{1}=\pi_{2}=p q_{i}$, where $i=1,2$. The equilibrium quantities, prices, and profits are:

$x_{i}^{F}=\frac{1}{3}$,

$p_{i}^{F}=\frac{1}{3}$

$\pi_{i}^{F}=\frac{1}{9}$

where superscript $F$ stands for the equilibrium values under the fixed-fee licensing contract.

The optimal licensing fee under the fixed-fee contract is:

$f=\pi_{i}^{F}-\pi_{1}^{B}=\frac{1}{9}-\frac{(3 \gamma-2+2 z)^{2}}{\gamma(4-\gamma)^{2}}$.

If $f \geq 0$, then the condition as follows has to be satisfied:

$$
\begin{aligned}
& 1-\frac{3}{2} \gamma-\frac{\sqrt{16 \gamma-8 \gamma^{2}+\gamma^{3}}}{6} \leq z \leq 1-\frac{3}{2} \gamma+ \\
& \frac{\sqrt{16 \gamma-8 \gamma^{2}+\gamma^{3}}}{6} \text {. }
\end{aligned}
$$


Hence, the total profit of the licensor is:

$\Pi_{2}{ }^{F}=\pi_{2}{ }^{F}+f=\frac{2}{9}-\frac{(3 \gamma-2+2 z)^{2}}{\gamma(4-\gamma)^{2}}$.

Again, since we assume that all products are sold in the third country, the social welfare of the home country under the fixed-fee licensing contract is:

$W_{2}{ }^{F}=\Pi_{2}{ }^{F}=\frac{2}{9}-\frac{(3 \gamma-2+2 z)^{2}}{\gamma(4-\gamma)^{2}}$.

\section{Royalty Licensing Contract}

We now consider the technology transfer by a royalty contract. After licensing, the two firms have the same product quality, i.e., $s_{1}=s_{2}=1$. However, the licensor charges a royalty rate $(\rho)$ to the licensee with respect to per product, and the two firms engage in homogeneous product competition. Hence, the inverse demand function that the two firms face is the same as Equation (4). The equilibrium quantities, prices, and profits are:

$q_{1}{ }^{R}=\frac{1-2 \rho}{3}$ and $q_{2}{ }^{R}=\frac{1+\rho}{3}$,

$p_{1}{ }^{R}=p_{2}{ }^{R}=\frac{1+\rho}{3}$,

$\pi_{1}{ }^{R}=\left(\frac{1-2 \rho}{3}\right)^{2}$ and $\pi_{2}^{R}=\frac{1}{9}+\frac{5}{9}\left(\rho-\rho^{2}\right)$.

Superscript $R$ stands for the equilibrium values under the royalty licensing contract. The total profit of the licensor is:

$\Pi_{2}{ }^{R}=\pi_{2}{ }^{R}+\rho q_{1}{ }^{R}=\left[\frac{1}{9}+\frac{5}{9}\left(\rho-\rho^{2}\right)\right]+\rho\left(\frac{1-2 \rho}{3}\right)$.

The optimal royalty rate that maximizes the patent holder's total profit is:

$\rho^{*}=\frac{4}{11}$.

Substituting $\rho^{*}=4 / 11$ into Equation (9) and Equation (10), we get the equilibrium values in the royalty licensing case as:

$q_{1}^{R^{*}}=\frac{1}{11}$ and $q_{2}^{R^{*}}=\frac{5}{11}$,

$p_{1}^{R^{*}}=p_{2}^{R^{*}}=\frac{5}{11}$,

$\pi_{1}^{R^{*}}=\frac{1}{121}$ and $\pi_{2}^{R^{*}}=\frac{29}{121}$.

The equilibrium value of social welfare is:

$W_{2}^{R^{*}}=\Pi_{2}^{R^{*}}=\pi_{2}^{R^{*}}+\rho^{*} q_{1}^{R^{*}}=\frac{3}{11}$.

\section{The Optimal Licensing Contract}

Comparing Equation (7) and Equation (12d), we find that the royalty licensing contract is superior to the fixed-fee licensing contract, i.e., $\Pi_{2}{ }^{R^{*}}>\Pi_{2}{ }^{F}$. We next need to examine whether the licensee is willing to accept the royalty licensing contract. Indeed, if $\pi_{1}{ }^{*}>\pi_{1}{ }^{B}$, then the licensee is willing to accept the royalty licensing contract. Hence, we present the condition that the licensee accepts the royalty licensing contract as follows:

$z_{0} \leq z \leq z_{1}$,

where $z_{0}=1-\frac{3}{2} \gamma-\frac{\sqrt{16 \gamma-8 \gamma^{2}+\gamma^{3}}}{22}$ and $z_{1}=1-\frac{3}{2} \gamma+$ $\frac{\sqrt{16 \gamma-8 \gamma^{2}+\gamma^{3}}}{22}$. On the contrary, if $\pi_{1}^{R^{*}}<\pi_{1}^{B}$, then the licensee rejects the royalty licensing contract. Similarly, the condition that the licensee rejects the royalty licensing contract is:

$z \geq z_{1}$ or $z \leq z_{0}$.

Hence, we propose two cases to discuss when firm 1 accepts the royalty licensing contract and when firm 1 rejects the royalty licensing contract.

\section{The Optimal Environmental Standard in the Third Country}

\section{Licensee Accepts the Royalty Licensing Contract}

When licensing happens, there are only high quality products in the third country market. Because there is no pollution after using the product, the social welfare function in the third country only encompasses consumer surplus. Hence, we get the social welfare function in the third country as:

$W_{T}^{R}=\int_{p_{i}^{R}}^{1}\left(u-p_{i}^{R}\right) d u=\frac{1}{2}\left(1-p_{i}^{R}\right)^{2}$.

Substituting Equation (12b) into Equation (14a), the optimal social welfare in the third country is:

$W_{T}^{R^{*}}=18 / 121$.

\section{Licensee Rejects the Royalty Licensing Contract}

When licensing does not happen, there are low quality products and high quality products in the third country market. The social welfare function is composed of consumer surplus and the environmental damage function. Following the general set-up, the environmental damage function is a strictly convex function of total emissions. We assume that the environmental damage function is $D\left(e q_{1}{ }^{B}\right)=\left(e q_{1}^{B}\right)^{2} / 2$, where $e=1-\gamma-z, \partial D / \partial e>0$, and $\partial^{2} D / \partial e \partial e>0$. Hence, the social welfare maximization problem for the third country can be formulated as follows:

$$
\underset{z}{\operatorname{Max}} W_{T}^{B}=\int_{\frac{u_{1}}{\gamma}}^{u_{1}}\left(u \gamma-p_{1}^{B}\right) d u+\int_{u_{1}}^{1}\left(u-p_{2}^{B}\right) d u-D,
$$

s.t. $z \geq z_{1}$ or $z \leq z_{0}$.

We use the Lagrange function to solve this problem and then get the equilibrium environmental standard as:

$$
\begin{aligned}
& z_{0}=1-\frac{3}{2} \gamma-\frac{\sqrt{16 \gamma-8 \gamma^{2}+\gamma^{3}}}{22} \text { or } z_{1}=1-\frac{3}{2} \gamma+ \\
& \frac{\sqrt{16 \gamma-8 \gamma^{2}+\gamma^{3}}}{22} \text {. }
\end{aligned}
$$




\section{The Optimal Environmental Standard}

The social welfare in the third country depends on the environmental standard decided by the government. When the environmental standard $z \in\left(z_{0}, z_{1}\right)$, the optimal social welfare in the third country is shown in Equation (15a). When the environmental standard $z=z_{0}$, the optimal social welfare is:

$$
\begin{gathered}
\gamma^{3}+472 \gamma^{2}+22 \gamma \sqrt{\gamma(4-\gamma)^{2}}- \\
W_{T}^{B Z 0}=\frac{17013 \gamma+60436-2750 \sqrt{\gamma(4-\gamma)^{2}}}{117128(4-\gamma)} .
\end{gathered}
$$

Similarly, when the environmental standard $z=z_{1}$, the optimal social welfare is:

$$
W_{T}^{B Z 1}=\frac{17013 \gamma+60436+2750 \sqrt{\gamma(4-\gamma)^{2}}}{117128(4-\gamma)} .
$$

W We use Fig. (1) to illustrate the magnitude of $W_{T}^{R^{*}}$, $W_{T}^{B Z 0}$, and $W_{T}^{B Z 1}$. Fig. (1) shows that $\mathrm{W}_{\mathrm{T}}^{\mathrm{BZ}_{1}}$ is always higher than $W_{T}^{R^{*}}$ and $W_{T}^{B Z 0}$. Hence, for maximizing the social welfare, the third country government chooses the optimal environmental standard as:

$z^{*}=z_{1}=1-\frac{3}{2} \gamma+\frac{\sqrt{16 \gamma-8 \gamma^{2}+\gamma^{3}}}{22}$.

We now have the following proposition.

Proposition 1 The third country government prefers various products in the market rather than zero-emission products.

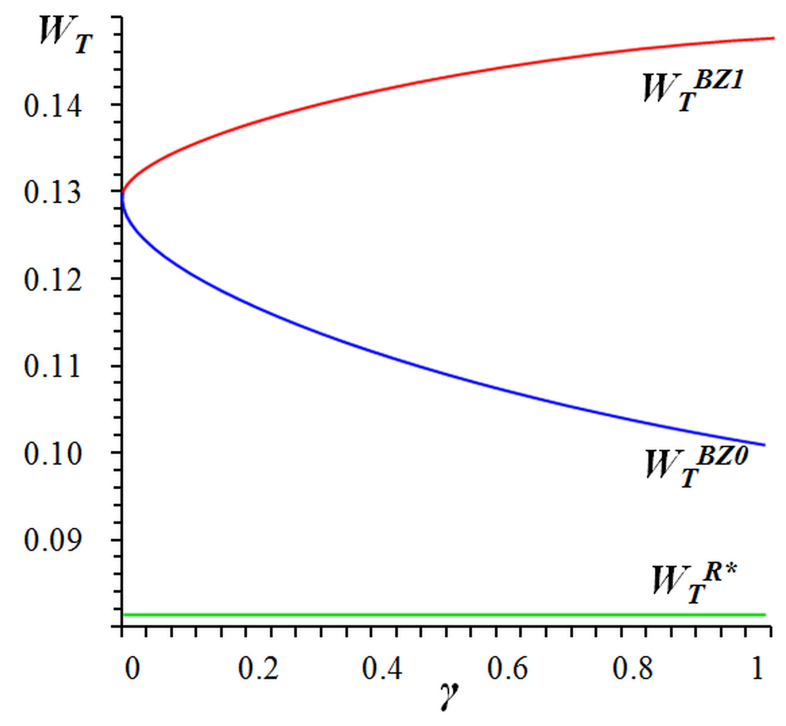

Fig. (1). Comparison of Social Welfare in the Third Country.

\section{EQUILIBRIUM ANALYSIS}

In the previous section we concluded that the third country government prefers a less strict environmental standard $z^{*}$, which can decrease the licensee's marginal production cost and in turn increase market competition to a degree. The social welfare of the third country will increase under high market competition. We also find that $W_{T}^{B Z 0}$ and $W_{T}^{B Z 1}$ are always higher than $W_{T}^{R^{*}}$ in Fig. (1), implying that the greater the variety of products is, the higher social welfare will be. Hence, a country with a less strict environmental standard and various products in the market caused by a less strict environmental standard may have high social welfare. We thus present the next proposition as follows:

Proposition 2 A country with various products in the market caused by a less strict environmental standard may have high social welfare.

According to the result above, we find that the third country government choosing the optimal environmental standard $z^{*}$ to induce the licensor's licensing behavior does not occur under our model. Our result is obviously different with the one in the previous literature, i.e., "Inside innovator always prefers the royalty licensing contract to the fixed-fee licensing contract under Cournot competition [12, 13]." Hence, we have the third proposition as follows:

Proposition 3 An inside innovator under Cournot competition may not prefer the royalty licensing contract when we consider that the product generates pollution through its use.

We next use comparative static analysis to examine the relationship between the optimal environmental standard $z^{*}$ and the substitution of product $\gamma$. The results are shown as follows:

$$
\frac{d z^{*}}{d \gamma}=-\frac{3}{2}+\frac{16-16 \gamma+3 \gamma^{2}}{44 \sqrt{16 \gamma-8 \gamma^{2}+\gamma^{3}}}<0 .
$$

When the substitution of the product increases, the optimal environmental standard in the third country will become stricter. An increase in the substitution of the product induces furious competition between the two firms and thus product quantity increases. The amount of emissions increases when the product quantity increases. Hence, a strict environmental standard is helpful to control the amount of emissions. We now have the fourth proposition as follows:

Proposition 4 The optimal environmental standard will become stricter when the substitution of the product increases.

Since the optimal environmental standard in the third country is not strict, the licensee's marginal production cost will not increase too much. This induces the licensee to not accept the licensor's licensing contract. Hence, the home firm with new technology and the foreign firm without new technology are engaged in Cournot competition in the third country. We show the two firms' equilibrium profits (two countries' social welfare) as follows:

$\pi_{1}^{B}=W_{1}^{B Z^{*}}=\frac{1}{121}$ and $\pi_{2}^{B}=W_{2}^{B Z^{*}}=\frac{144-11 \gamma-\sqrt{\gamma(4-\gamma)^{2}}}{22(4-\gamma)}$.

Recalling Equation (2d) and since the equilibrium output is non-negative, $z^{*}$ needs to satisfy the condition $1-\frac{3}{2} \gamma \leq z^{*}$ $\leq 1-\gamma$, i.e., the reasonable region of $\gamma$ is $\gamma \in[0.124,1]$. We 
use Fig. (2) to illustrate the relationship between the two firms' optimal profits (two countries' optimal social welfare) as follows.

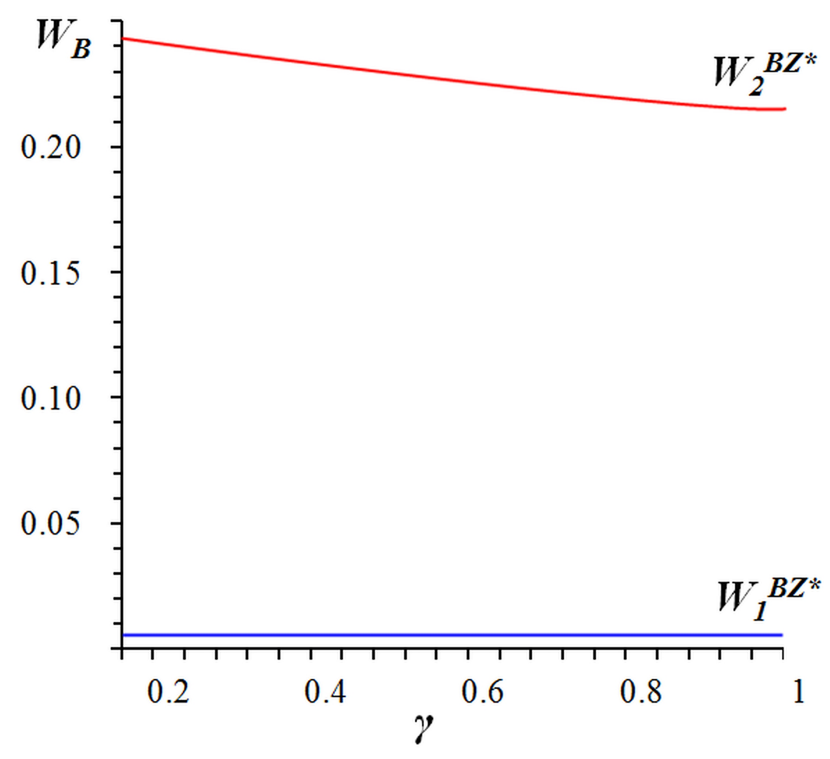

Fig. (2). Comparison of Two Countries' Optimal Social Welfare.

Fig. (2) presents that the home firm's profit (the home country's social welfare) decreases when the substitution of the product increases. This is because a high substitution of product induces furious market competition and pushes the home firm's profit (home country's social welfare) down. However, the substitution of the product does not affect the foreign firm's profit, because an increase in the foreign firm's profit through quality promotion is used for emission abatement.

\section{CONCLUDING REMARKS}

We develop a three-country model in which two countries export heterogeneous products to the third country and undergo Cournot competition. We use this model to analyze the influence of licensing behavior when the third country government maximizes social welfare by deciding upon an environmental standard.

The analysis herein reveals that the third country government prefers a market with various products rather than a zero-emission market in order to maximum its social welfare, and under this situation, the third country government prefers a less strict environmental standard rather than a strict one. A market with various products induces the magnitude of consumer surplus to be larger than the environmental damages under a less strict environmental standard. However, the environmental standard in the third country will become stricter, because the increasing substitution of products creates furious competition. So as to decrease pollution after the products are used, the third country government will adopt a strict environmental standard.

In the aspect of licensing, the high quality firm prefers the royalty licensing contract to the fixed-fee licensing contract, because the royalty licensing contract will push the low quality firm's marginal production cost to decrease its outputs. However, the low quality firm is not willing to accept the high quality firm's licensing contract when the third country government prefers a less strict environmental standard. Hence, the licensing contract does not exist in our model, and it also induces a market to be full of various quality goods.

We finally compare the social welfare of the two countries, and find that the social welfare of the high quality firm is always higher than that of the low quality firm. However, the social welfare of the high quality firm will decrease when the substitution of products increases, because high substitution raises the degree of market competition, which induces a drop in the high quality firm's profit and also induces the social welfare of the home country to decrease. In addition, the social welfare of the foreign country is constant no matter what the substitution of products is. Although an increase in the substitution of products creates excess profit for the low quality firm, the excess profit is used to cover the cost of pollution abatement. Therefore, the social welfare of the foreign country does not change when the substitution of product changes.

Our model fully illustrates a real case involving a high quality motorbike from Taiwan's Sanyang Industry Corporation (SYM) and a low quality motorbike from Vietnam Manufacturing and Export Processing Holdings (VMEPH), both of which are exported to mainland China and engage in quantity competition. The government of mainland China executes a less strict environmental standard to maximize social welfare. Zhang Yue, one of the wealthiest entrepreneurs in mainland China and founder and chairman of Broad Group, says that "There are laws on everything, but I do not think there are enough laws on energy consumption (in China)". Although there are some local Chinese manufacturers with an environmental consciousness such as Broad Group, the disparity of quality among products still exists in the domestic market there.

In addition to the motorbike industry, many other things also pollute the environment, such as volatile organic compounds (VOCs), which are organic chemicals with a high vapor pressure at ordinary room temperature. Some VOCs are toxins and cause harm to human health or the environment, and most people are exposed to VOCs anytime and anywhere. Canada and the U.S. have already instituted emission laws for VOCs, and some paint producers offer products that contain low VOCs or no VOCs, such as ICI, Nippon, and Safecoat. Most governments still have a less strict environmental attitude toward these chemical substances, and therefore there is no technology transfer between these producers.

We also note another inverse and stricter case of a third country with a substitution of products. In 2013 the French government announced that the latest Mercedes-Benz models, like the A-Class, B-Class, and SL-Class, would be blocked from selling polluting vehicles according to the country's mobile air-conditioning system (MAC) directive, because these models adopt an older form of air-conditioner refrigerant (R134a) that reheats climatic risk (PRP) to over 150 (the equivalent of 150 kilograms of $\mathrm{CO}_{2}$ ). Some other car manufacturers like General Motors, Ford, and Toyota have avoided this since 2008 by replacing R134a with the 
gas HFO-1234yf. Although HFO-1234yf is almost a zeroemission green refrigerant, it still has some dangerous elements to it, such as being flammable and emitting toxic gases into the atmosphere when a fire erupts. Mercedes-Benz complained to the European Commission that the emission standards in 2020 are too strict, and that there is no enterprise or government that can afford the huge expenses to develop a new technology. It also took administrative litigation against the French government. On August 27, 2013, France's top administrative court ordered the government to lift a controversial ban on the registration of several Mercedes-Benz models, and the Council of State found that continued use of R134a does not pose an immediate environmental threat [22]. Although the French government was set back in its environmental efforts, it is going to raise the maximum levy on purchases of vehicles with high emissions to 8,000 Euros from 6,000 in 2014.

Our model can be extended to various environmental institutions in the future - for example, clean development mechanism (CDM), joint implementation (JI), and emission trade (ET). These three kinds of environmental institutions are regulated by the Kyoto Protocol in order to decrease $\mathrm{CO}_{2}$ emissions. Another environmental aspect, the emission tax, can also be discussed in an extended model.

\section{NOMENCLATURE}

\begin{tabular}{|c|c|}
\hline Symbol & Definition \\
\hline$s_{1}$ & $\begin{array}{l}\text { Foreign firm's (firm 1) product quality; let } s_{1} \\
=\gamma \text {, where } \gamma \in(0,1) .\end{array}$ \\
\hline$s_{2}$ & $\begin{array}{l}\text { Home firm's (firm 2) product quality; let } s_{2}= \\
1 \text {. }\end{array}$ \\
\hline$V$ & Consumer's utility function. \\
\hline$u$ & $\begin{array}{l}\text { Uniform distribution with the destiny function } \\
\text { being } 1 \text {. }\end{array}$ \\
\hline$p_{i}$ & Firm $i$ 's product price, where $i=1$ or 2 . \\
\hline$e_{1}$ & $\begin{array}{l}\text { Pollution amount per unit for the low quality } \\
\text { product; let } e_{1}=1-\gamma \text {. }\end{array}$ \\
\hline$e_{2}$ & $\begin{array}{l}\text { Pollution amount per unit for the high quality } \\
\text { product; let } e_{2}=0 \text {. }\end{array}$ \\
\hline$z$ & $\begin{array}{l}\text { Third country's environmental standard, } \\
\text { where } z \in(0,1) \text {. }\end{array}$ \\
\hline$c$ & Per unit product abatement cost, where $c=1$ \\
\hline$q_{i}$ & $\begin{array}{l}\text { Firm } i \text { 's product demand quantity, where } i=1 \\
\text { or } 2 \text {. }\end{array}$ \\
\hline$\pi_{i}$ & Firm $i$ 's profit, where $i=1$ or 2 . \\
\hline$f$ & $\begin{array}{l}\text { Optimal licensing fee under the fixed-fee } \\
\text { contract. }\end{array}$ \\
\hline$\rho$ & Royalty rate. \\
\hline$D$ & Environmental damage function. \\
\hline$W_{T}^{R^{*}}$ & $\begin{array}{l}\text { Optimal social welfare for the third country } \\
\text { under the royalty licensing method. }\end{array}$ \\
\hline$W_{T}^{B Z 0}$ & Social welfare for the third country under the \\
\hline
\end{tabular}

\begin{tabular}{|l|l|}
\hline & $\begin{array}{l}\text { environmental standard } z_{0} \text { and the benchmark } \\
\text { model. }\end{array}$ \\
\hline$W_{T}^{B Z 1}$ & $\begin{array}{l}\text { Social welfare for the third country under the } \\
\text { environmental standard } z_{1} \text { and the benchmark } \\
\text { model. }\end{array}$ \\
\hline$W_{i}^{B}$ & $\begin{array}{l}\text { Optimal social welfare for the country } i \text { under } \\
\text { the benchmark model, where } i=1 \text { or } 2 .\end{array}$ \\
\hline$W_{i}^{B Z^{*}}$ & $\begin{array}{l}\text { Optimal social welfare for the country } i \text { under } \\
\text { the optimal environmental standard } z^{*} \text { and the } \\
\text { benchmark model, where } i=1 \text { or } 2 .\end{array}$ \\
\hline
\end{tabular}

\section{CONFLICT OF INTEREST}

The authors confirm that they do not have any conflict of interests concerning the content of this article.

\section{ACKNOWLEDGEMENTS}

The authors thank an editorial board member and an anonymous referee for their valuable comments. Financial support from Taiwan's National Science Council is gratefully acknowledged (NSC 97-2410-H-424-001 and NSC 102-2410-H-424-020).

\section{REFERENCES}

[1] Daly H. Problems with free trade: Neoclassical and steady-state perspectives. In: Zaelke D, Orbuch P, Housman RF, Eds. Trade and the environment: law, economics, and policy. Washington, DC: Island Press, 1993.

[2] Smart China Sourcing, Motorcycle trikes: Expensive emission standards ground US, EU exports, 2009; Available from: http:// www.smartchinasourcing.com/auto-parts-accessories/motorcycle-tr ikes-expensive-emission-standards-ground-us-eu-ex.html

[3] Chang MC, Hu JL. Environmental technology licensing under emission-equivalent environmental taxes and standards. Open Environ Sci 2013; 7: 14-20.

[4] Barrett S. Strategic environmental policy and international trade. J Public Econ 1994; 54: 325-38.

[5] Kayalica MÖ, Lahiri S. Strategic environmental policies in the presence of foreign direct investment. Environ Resour Econ 2005; 30: 1-21.

[6] Lahiri S, Ono Y. Export-oriented foreign direct investment, local content requirement, and profit taxation. Econ J 1998; 108: 444-57.

[7] Dean JM. Trade and the environment: a survey of the literature Policy Research Working Paper Series 966, The World Bank, 1992.

[8] Gallini N. Deterrence by market sharing: a strategic incentive for licensing. Amer Econ Rev 1984; 74: 931-41.

[9] Gallini N, Winter R. Licensing in the theory of innovation. Rand J Econ 1985; 16: 237-52.

[10] Katz M, Shapiro C. On the licensing of innovations. Rand J Econ 1985; 16: 504-20.

[11] Kamien MI, Tauman Y. Fee versus royalties and the private value of a patent. Quart J Econ 1986; 101: 471-91.

[12] Kamien MI. Patent licensing. Handbook of Game Theory with Economic Applications. In: Aumann RJ, Hart S, Eds. Chapter 11, 1, North Holland: Elsevier Science Publishers 1992; pp. 331-54.

[13] Sen D, Tauman Y. General licensing schemes for a cost-reducing innovation. Games Econ Behav 2007; 59: 163-86.

[14] Li CY, Song JA. Technology licensing in a vertically differentiated duopoly. Japan World Econ 2009; 21: 183-90.

[15] The Epoch Times, Vehicle's new emission standard in China is the same as one in Europe, 2007; Available from: http://www.epoch times.com/b5/7/6/30/n1759657.html

[16] Jiangsu Jiuding New Material Co., Fiberglass electric vehicle bodyworks, 2009; Available from: http://www.gasgoo.com/auto-partstrade/image-LKTTSTM/Fiberglass-Electric-Vehicle-Bodyworks.html

[17] Wang XH. Fee versus royalty licensing in a differentiated Cournot duopoly. J Econ Bussin 2002; 54: 253-66. 
[18] Chang MC, Hu JL, Tzeng GH. Decision making on strategic environmental technology licensing: fixed-fee versus royalty licensing methods. Int J Info Technol Decision Mak 2009; 8: 60924.

[19] Brander JA, Spencer BJ. Export subsidies and international market share rivalry. J Int Econ 1985; 18: 83-100.
[20] Motta M. Endogenous quality choice: price $v s$ quantity competition. J Industr Econ 1993; 41: 113-31.

[21] Avenel E, Caprice S. Upstream market power and product line differentiation in retailing. Int J Industr Organiz 2006; 24: 319-34.

[22] Reuters website, 2013; Available from: http://www.reuters.com/ article/2013/09/16/us-france-autos-idUSBRE98F0UM20130916

(C) Chang and Pan; Licensee Bentham Open.

This is an open access article licensed under the terms of the Creative Commons Attribution Non-Commercial License (http: //creativecommons.org/licenses/by$\mathrm{nc} / 3.0 /$ ) which permits unrestricted, non-commercial use, distribution and reproduction in any medium, provided the work is properly cited. 